\title{
Simple One-Pot Synthesis of Sulfonic-Acid-Functionalized Silica for Effective Catalytic Esterification of Levulinic Acid
}

\author{
Desinta Dwi Ristiana, Suyanta Suyanta, and Nuryono Nuryono* \\ Department of Chemistry, Faculty Mathematics and Natural Sciences, Universitas Gadjah Mada, \\ Sekip Utara, PO BOX BLS 21, Yogyakarta 55281, Indonesia
}

* Corresponding author:

tel: $+62-8156800908$

email:nuryono_mipa@ugm.ac.id

Received: August 9, 2021

Accepted: September 24, 2021

DOI: $10.22146 /$ ijc. 68301

\begin{abstract}
Silica functionalized with sulfonic acid catalyst $\left(\mathrm{SiO}_{2}-\mathrm{SO}_{3} \mathrm{H}\right)$ was synthesized through a one-pot method and evaluated as the catalyst material for esterification of levulinic acid in an excess amount of ethanol. Sodium silicate solution was used as the silica source, and then a silane coupling agent, namely GPTMS, was used to incorporate the sulfonic group of 2-aminoethanesulfonic acid (AS) into the silica. Functionalization of AS using GPTMS in the slightly acidic condition has been successfully carried out based on the characterization with FTIR, SEM-EDX, and TGA measurements. Catalyst with the AS to $\mathrm{SiO}_{2}$ molar ratio of 5:6 $\left(\mathrm{SiO}_{2}-\mathrm{SO}_{3} \mathrm{H}(5)\right)$ showed the highest acid content $(1.02$ mmol $\left.\mathrm{g}^{-1}\right)$ and the highest conversion of levulinic acid (70\%). The reaction followed pseudo-first-order with the rate constant of $0.00414 \mathrm{~min}^{-1}$. Catalyst material was regenerated by washing with alcohol and water, and the catalyst material can be reused at least for 3 cycles. From this study, the $\mathrm{SiO}_{2}-\mathrm{SO}_{3} \mathrm{H}$ produced from a green process is an effective catalyst to produce esters used in fuel additives.
\end{abstract}

Keywords: silica acid catalyst; coupling agent; one-pot method; esterification; levulinic acid

\section{- INTRODUCTION}

Liquid acid catalysts are widely used in industrial processes because of their high activity and selectivity [1]. However, these catalysts are avoided because of the toxicity, separation difficulty, and waste production. Solid acid catalysts then become the solution to overcome drawbacks in the liquid acid catalyst. The silica-based catalyst has been developed among many solid acid catalysts because it is widely abundant, biocompatible, non-toxic, thermally stable, and easy to synthesize in mild conditions [2]. Silica-based material has been highly explored because it can easily be modified with other molecules or materials because of its surface silanol ( $\mathrm{Si}-$ $\mathrm{OH})$ groups. Silanol groups themselves are weak acid sites that cannot be used directly without modification. Silica was compatible with organic substances and was often modified with organic compounds for different purposes such as adsorbent, catalyst, and ion-exchanger [3-5]. A silica network can be formed via a sol-gel process consisting of hydrolysis and condensation silica precursors such as silica alkoxides or silica salts with acid or base catalyst.

One particular challenge in synthesizing acid catalysts is incorporating acid sites onto weak acid, an inorganic material such as silica. Several reports have been demonstrated to increase its acidity. Xiong et al. [6] incorporated $\mathrm{HSO}_{3} \mathrm{Cl}$ directly onto the surface of silica materials to form a $\mathrm{SiO}_{2}-\mathrm{SO}_{3} \mathrm{H}$ acid catalyst. However, $-\mathrm{SO}_{3} \mathrm{H}$ groups were not firmly attached to $\mathrm{SiO}_{2}$ and were accessible to leach. Berbar et al. [4] used sulfonated polyethersulfone membrane (PES) to increase the acidity of silica materials. However, the sulfonation degree of PES was limited only up to $27 \%$. Ziarani et al. [5] used organosilane 3-mercaptopropyltrimethoxysilane (MPTMS) as $-\mathrm{SO}_{3} \mathrm{H}$ groups precursor whereas $-\mathrm{SH}$ groups were oxidized with strong oxidants such as $\mathrm{H}_{2} \mathrm{O}_{2}$ and $\mathrm{HNO}_{3}$. This research seems promising mainly because of the strong covalent bond formed between acid sites and silica surfaces. Amidst its advantage, the synthesis method needs to use a very toxic oxidizing 
agent that was not safe for the environment. New approaches need to be developed to form silica acid catalysts without harming the environment.

Silica modification with organosilane seems pretty interesting with the advantages to adding organic moieties that already bonded in organosilane onto silica by strong covalent bonding [7]. Organosilane consists of an organic functional group and three alkoxy groups. Similar to the silica alkoxides, it can undergo hydrolysis and condensation, leaving organic moiety on the external sites [8]. The organic moiety of organosilane can be used directly, and it can also be used as a coupling agent to bridge other organic substances onto silica materials. The organic sites of organosilane can be further modified with another organic substance to change the functional groups as desired [3]. Through this crosslinking, the preferred organic groups can form strong covalent bonds with silanols from silica materials. One of the silane coupling agents often used is 3glycidoxypropyltrimethoxysilane (GPTMS). GPTMS is often labeled as "network former" because it has an epoxy ring that is reactive with nucleophile groups [7,9-10]. Several experiments have been reported using GPTMS as a coupling agent between silica and many organic substances such as chitosan [9], alginate [11], ethylenediamine, and diethylenetriamine [12-13]. Most of them take advantage of epoxy ring-opening of GPTMS through nucleophilic substitution with nucleophilic groups. However, none of these experiments was conducted to obtain silica acid catalysts. Previously, PallaRubio et al. [7] incorporated chitosan onto GPTMS and caused crosslinking through condensation with silanol groups. Amine groups of chitosan act as a nucleophile to encourage ring-opening of the epoxide group in GPTMS.

Various studies have shown that the ring-opening of epoxide groups could happen in acid solutions such as acetic acid [7] and formic acid [14]. Gabrielli et al. [15] reported that ring-opening of epoxide group in GPTMS could be conducted at slightly acidic conditions to undergo nucleophilic attack. In neutral $\mathrm{pH}$, the catalysis will be too slow. Meanwhile, it can cause hydrolysis of epoxide ring to form diol group that hinders the nucleophilic reaction in the too acidic condition. In basic conditions, polymerization of silanol groups will dominate the ring-opening reaction. Incorporating an organic substance containing nucleophilic group onto GPTMS might cause another challenge because it requires appropriate conditions to maximize nucleophilic attack and maintain the polymerization of silanol groups.

In silica modified with organic substance with the presences of GPTMS, generally, silica is first isolated and functionalized with GPTMS using grafting method and then reacted with an organic molecule to form crosslinking between silica and organic molecules [9]. However, this method is limited by multi-step processes, high cost, strict preparation conditions, and often uses many additional reagents, which are not environmentally friendly [16]. In addition, the surface of pre-synthesized silica may have different reactivity towards modifier molecules. Silane groups of modifier molecules may also undergo self-condensation before reacting with silica surfaces resulting in non-uniform particles [17].

In contrast with the grafting method, the one-pot synthesis method offers many advantages, such as reducing synthesis steps and using additional reagents [18]. This method reduces the total synthesis time, which is more economical and efficient. Moreover, more organic moieties can be bonded onto silica using the one-pot co-condensation method [19]. Epoxide group of GPTMS can undergo nucleophilic attack by the amine group in slightly acidic conditions. The sulfonic acid group is at the end of the structure and acts as the acid site for catalysis. By crosslinking with GPTMS, the sulfonic group can bond tightly onto the silica surface.

In the present study, we develop a new strategy that is simple, non-toxic, and environmentally friendly to synthesize silica-based acid catalysts with covalent bonds between the epoxy group in GPTMS and the amine group in 2-aminoethanesulfonic acid. Another objective of this study is to examine the catalyst activity in the esterification of levulinic acid with ethanol, including the evaluation of the reaction kinetics. Levulinic esters are often used as an additive to blend with diesel or biodiesel fuel where they can give great 
performances such as high lubricity, low toxicity, flash point stability, and good cold flow properties [20]. Fernandes et al. [21] reported that levulinic acid could be used up to $5 \mathrm{wt}$ \% in biodiesel engines without further modification.

\section{- EXPERIMENTAL SECTION}

\section{Materials}

The chemicals used for the synthesis of catalysts included sodium silicate $\left(\mathrm{Na}_{2} \mathrm{SiO}_{3}\right)$ solution $\left(\mathrm{SiO}_{2} 25.5-\right.$ 28.5\%, $\mathrm{Na}_{2} \mathrm{O} 7.5-8.5 \%$, Aldrich) as a silica source, 3glycidoxypropyltrimethoxysilane (GPTMS, 98.0\%, Aldrich), and 2-aminoethanesulfonic acid (99.4\% Focus Herb). Levulinic acid (98.0\%, Aldrich) and ethanol (99.8\%, Aldrich) were used to evaluate the activity of catalysts.

\section{Instrumentation}

The characterization of functional groups in the materials was performed by FTIR spectrometer using Shimadzu Prestige $21\left(4000-400 \mathrm{~cm}^{-1}\right)$ with the $\mathrm{KBr}$ pellet method. The thermogravimetric analysis (TGA) was performed on Mettler Toledo by measuring the weight loss materials in increasing temperature of 303-973 K at a rate of $10 \mathrm{~K} \mathrm{~min}^{-1}$ under $\mathrm{N}_{2}$ atmosphere. The morphology and the elemental composition were analyzed with the scanning electron microscopy (SEM) images (JEOL JSM-6510LA) equipped with an energy dispersive X-ray spectrometer (EDX). Gas Chromatography-Mass Spectroscopy (Thermo scientific Trace 1310 Gas Chromatograph-ISQ LT Single Quadrupole Mass Spectrometer) was used to confirm the presence of ethyl levulinate.

\section{Procedure}

\section{Synthesis of catalyst}

The synthesis was carried out by varying the amount of GPTMS-AS from 3 to 6 mmol. First, 3-6 mmol (0.38$0.76 \mathrm{~g}$ ) of 2-aminoethanesulfonic acid (AS) was dissolved in $10 \mathrm{~mL}$ of $0.05 \mathrm{M}$ formic acid. Afterward, the GPTMS of the same amount (3-6 mmol, 0.71-1.42 g) was added, and the reaction was allowed to proceed for $2 \mathrm{~h}$ at room temperature to form GPTMS-AS. This step was done to form a covalent bond between two structures. Then, a solution of $\mathrm{Na}_{2} \mathrm{SiO}_{3}(2 \mathrm{~mL}, 6 \mathrm{mmol} \mathrm{SiO}$ ) and GPTMSAS was reacted under a magnetic stirrer with the addition of $5 \mathrm{M} \mathrm{HCl}$ solution dropwise until the gel was formed. The gel was left for $24 \mathrm{~h}$ at room temperature to strengthen the bond, and the resulting gel was dried at $60{ }^{\circ} \mathrm{C}$ for $24 \mathrm{~h}$ and named as $\mathrm{SiO}_{2}-\mathrm{SO}_{3} \mathrm{H}$. The dried gel was ground and washed with alcohol to remove residues. The composition of precursors and code of the resulted products are summarized in Table 1 . The obtained materials were characterized to identify the functional groups with FTIR, morphology and chemical composition with SEM-EDX, and the acidity with volumetry.

\section{Determination of $\mathrm{SiO}_{2}-\mathrm{SiO}_{3} \mathrm{H}$ acidity}

Acidity was determined with a volumetric method. Excess of $\mathrm{NaOH}$ solution was used to measure the total of acidic groups in catalysts [22]. After equilibrium was reached, the solution was back titrated with $\mathrm{HCl}$ solution. A small number of catalysts $(0.1 \mathrm{~g})$ were reacted with $10 \mathrm{~mL} \mathrm{NaOH}$ solution $0.05 \mathrm{M}$ for $60 \mathrm{~min}$. Non-adsorbed $\mathrm{NaOH}$ was determined using the back titration method with $0.05 \mathrm{M} \mathrm{HCl}$ solution and phenolphthalein as the indicator.

\section{Esterification of levulinic acid}

The catalytic performance of various catalysts was tested on levulinic esterification with excess ethanol, as shown in Fig. 1. The optimum condition of esterification was first determined using a catalyst with the highest acid content. As much as $1 \mathrm{~g}(8.4 \mathrm{mmol})$ of levulinic acid and $2.5 \mathrm{~mL}$ ( $84 \mathrm{mmol}$ ) ethanol (the molar ratio of 1:10) were mixed with $50 \mathrm{mg}$ ( $5 \mathrm{wt} . \%$ ) of catalyst. The reaction was performed by heating the mixture of levulinic acid, ethanol, and the catalyst at $70{ }^{\circ} \mathrm{C}$ in a three-necked flask equipped with a stirrer and a condenser for $6 \mathrm{~h}$. After the reaction, the catalysts were separated from liquid mixtures

Table 1. Composition and code of catalysts produced

\begin{tabular}{cccc}
\hline $\begin{array}{c}\mathrm{AS} \\
(\mathrm{g} ; \mathrm{mmol})\end{array}$ & $\begin{array}{c}\text { GPTMS } \\
(\mathrm{g} ; \mathrm{mmol})\end{array}$ & $\begin{array}{c}\mathrm{Na}_{2} \mathrm{SiO}_{3} \\
\left(\mathrm{~mL} ; \mathrm{mmol} \mathrm{SiO}_{2}\right)\end{array}$ & $\begin{array}{c}\text { Product } \\
\text { code }\end{array}$ \\
\hline $0.38 ; 3$ & $0.71 ; 3$ & $2 ; 6$ & $\mathrm{SiO}_{2}-\mathrm{SO}_{3} \mathrm{H}(3)$ \\
$0.50 ; 4$ & $0.95 ; 4$ & $2 ; 6$ & $\mathrm{SiO}_{2}-\mathrm{SO}_{3} \mathrm{H}(4)$ \\
$0.63 ; 5$ & $1.18 ; 5$ & $2 ; 6$ & $\mathrm{SiO}_{2}-\mathrm{SO}_{3} \mathrm{H}(5)$ \\
$0.76 ; 6$ & $1.42 ; 6$ & $2 ; 6$ & $\mathrm{SiO}_{2}-\mathrm{SO}_{3} \mathrm{H}(6)$ \\
\hline
\end{tabular}


<smiles>CC(=O)CCC(=O)OCCOCC#CC(=O)CCC(=O)OC[18OH]</smiles>

Fig 1. Esterification reaction of levulinic acid

with the filtration. The liquid mixtures of product and unreacted levulinic acid were collected and titrated with $\mathrm{KOH}$ and phenolphthalein as the indicator. The conversion was calculated according to Eq. (1). GC-MS confirmed the presence of ethyl levulinate product.

Conversion $(\%)=1-\frac{(\mathrm{M} \times \mathrm{V}) \text { of } \mathrm{KOH}}{\mathrm{mol} \text { of acid total }} \times 100$

Different levulinic acid:ethanol molar ratios (1:10 and 1:15) and percentage of the catalyst (10 wt.\%) were tested as the comparison. The esterification conditions with the highest conversion were then used to determine the catalysts' optimum reaction time and reusability. The levulinic acid:ethanol molar ratio of 1:10 gave the highest conversion $(\sim 32 \%)$ when the reaction used 5 wt.\% of catalyst for $3 \mathrm{~h}$, and this condition was then used for further experiments.

A reusability test was also performed using the used catalysts that have been washed with alcohol and water. Esterification of levulinic acid with regenerated catalyst was performed at the same condition for $4 \mathrm{~h}$. With the same proportion (molar ratio 1:10 and $5 \mathrm{wt} . \%$ catalyst), the composition of levulinic acid, ethanol, and catalyst used for the reusability test was 4 times higher because of its possible mass decrease of the catalyst after reaction and washing treatment.

\section{Kinetic study}

The kinetics of levulinic acid esterification were evaluated based on the levulinic acid conversion at various times (1, 2, 4, 5, and $6 \mathrm{~h})$. Esterification of levulinic acid and ethanol is a reversible reaction with the reaction rate presented in Eq. (2).

Levulinic acid $\left(\mathrm{C}_{\mathrm{A}}\right)+$ Ethanol $\left(\mathrm{C}_{\mathrm{B}}\right)$ $\rightleftarrows$ Ethyl Levulinate $\left(\mathrm{C}_{\mathrm{C}}\right)+$ Water $\left(\mathrm{C}_{\mathrm{D}}\right)$

$-\mathrm{r}_{\mathrm{A}}=\frac{-\mathrm{dC}_{\mathrm{A}}}{\mathrm{d}_{\mathrm{t}}}=\mathrm{k}_{1} \mathrm{C}_{\mathrm{A}}^{\alpha} \mathrm{C}_{\mathrm{B}}^{\beta}-\mathrm{k}_{2} \mathrm{C}_{\mathrm{C}}^{\gamma} \mathrm{C}_{\mathrm{D}}^{\delta}$

where $C_{A}, C_{B}, C_{c}$, and $C_{D}$ are the concentrations of levulinic acid, ethanol, ethyl levulinate, and water, with the reaction orders of $\alpha, \beta, \gamma$, and $\delta$, respectively. $\mathrm{k}_{1}$ is the kinetic constant of ethyl levulinate formation, and $\mathrm{k}_{2}$ is the kinetic constant of its reverse reaction.

The kinetic model could be simplified based on the following assumption [23]: The initial ethanol concentration was much higher than the initial concentration of levulinic acid; thus, $C_{B}$ could be assumed constant through the reaction; The excess ethanol could push forward the equilibrium reaction and was considered an irreversible reaction as $k_{1} \gg>k_{2}$.

Thus, the kinetic model was simplified as Eq. (3) and (4), where $\mathrm{k}=\mathrm{k}_{1} \mathrm{C}_{\mathrm{B}}^{\beta}$.

$\begin{aligned}-\frac{\mathrm{dC}_{\mathrm{A}}}{\mathrm{dt}} & =\mathrm{k}_{1} \mathrm{C}_{\mathrm{A}}^{\alpha} \mathrm{C}_{\mathrm{B}}^{\beta} \\ -\frac{\mathrm{dC}_{\mathrm{A}}}{\mathrm{dt}} & =\mathrm{kC}_{\mathrm{A}}^{\alpha}\end{aligned}$

When levulinic acid conversion was assumed as $\mathrm{x}$, the concentration of levulinic acid can be written as $\mathrm{C}_{\mathrm{A}}=$ $\mathrm{C}_{\mathrm{A}_{0}}(1-\mathrm{x})$, where $\mathrm{C}_{\mathrm{A} 0}$ was referred to as the initial concentration of levulinic acid. Then Eq. (4) can be transformed to Eq. (5) and (6).

$$
\begin{aligned}
& -\frac{\mathrm{d}(1-\mathrm{x})}{\mathrm{dt}}=\frac{\mathrm{k}}{\mathrm{C}_{\mathrm{A}_{0}}}\left[\mathrm{C}_{\mathrm{A}_{0}}(1-\mathrm{x})\right]^{\alpha} \\
& \frac{\mathrm{dx}}{\mathrm{dt}}=\frac{\mathrm{k}}{\mathrm{C}_{\mathrm{A}_{0}}}\left[\mathrm{C}_{\mathrm{A}_{0}}(1-\mathrm{x})\right]^{\alpha}
\end{aligned}
$$

Using the integration method, the equation can be solved for different order reactions $(\alpha=0,1,2)$ based on the experimental results.

\section{- RESULTS AND DISCUSSION}

FTIR analysis was conducted to ensure the successful reaction of GPTMS and AS and the success of $\mathrm{SiO}_{2}$ and GPTMS-AS polymerization. Fig. 2 shows absorption spectra of precursors (GPTMS and AS) and synthesized $\mathrm{SiO}_{2}-\mathrm{SO}_{3} \mathrm{H}$. FTIR spectra of GPTMS shown at 2900 and $2800 \mathrm{~cm}^{-1}$ are due to asymmetric and symmetric stretching of $\mathrm{C}-\mathrm{H}$ composed from the organic side of GPTMS. The broad peak at $1090 \mathrm{~cm}^{-1}$ corresponds to the stretching vibration of $\mathrm{Si}-\mathrm{O}-\mathrm{CH}_{3}$ [24]. The characteristic of the epoxide group can be observed from the sharp peak at $850 \mathrm{~cm}^{-1}$ that corresponds to asymmetric $\mathrm{C}-\mathrm{O}-\mathrm{C}$ vibration [25]. The $\mathrm{C}-\mathrm{O}$ stretching vibrations were observed at $1400 \mathrm{~cm}^{-1}$ [26]. The presence of the sulfonic group in AS is 
observed at 1200 and $1050 \mathrm{~cm}^{-1}$, representing stretching asymmetric and symmetric of $\mathrm{S}=\mathrm{O}$, respectively [27].

The success of GPTMS functionalization with AS can be observed from the FTIR spectra of synthesized $\mathrm{SiO}_{2}-\mathrm{SO}_{3} \mathrm{H}$ catalysts. It is indicated by the absence of a prominent peak at $850 \mathrm{~cm}^{-1}$, which represents asymmetric $\mathrm{C}-\mathrm{O}-\mathrm{C}$ stretching vibrations. The peaks corresponding to the epoxide ring and sulfonic group are not observed mainly due to the complete ring-opening or the overlapping band with the strong $\mathrm{Si}-\mathrm{O}-\mathrm{Si}$ absorption band at $1200-1050 \mathrm{~cm}^{-1}$. However, it can be observed that the band around $1200-1050 \mathrm{~cm}^{-1}$ in the spectra of $\mathrm{SiO}_{2}-\mathrm{SO}_{3} \mathrm{H}$ catalyst appears very sharp, indicating the character of the $\mathrm{S}=\mathrm{O}$ band. The character of the $\mathrm{N}-\mathrm{H}$ bond also appears slightly around $3200-3000 \mathrm{~cm}^{-1}$.

Fig. 3 shows FTIR spectra of $\mathrm{SiO}_{2}-\mathrm{SO}_{3} \mathrm{H}$ materials prepared using various concentrations of GPTMS-AS. The small shoulder at $950 \mathrm{~cm}^{-1}$ is due to $\mathrm{Si}-\mathrm{OH}$ groups [25], the peak at $1200-1050 \mathrm{~cm}^{-1}$ corresponds to $\mathrm{Si}-\mathrm{O}-\mathrm{Si}$ stretching vibration, and the broad absorption around $3500 \mathrm{~cm}^{-1}$ is due to $\mathrm{O}-\mathrm{H}$ stretching vibrations from hydroxyl groups. This peak overlapped with secondary amines (-NH-), which appear at $3350-3310 \mathrm{~cm}^{-1}$ after the reaction of GPTMS and AS $[7,26]$. The absorption of $\mathrm{Si}-\mathrm{O}-\mathrm{Si}$ at $750 \mathrm{~cm}^{-1}$ [25] increased when more GPTMS functionalized sulfonic acid was added. Increased sharpness around $1250-1200 \mathrm{~cm}^{-1}$ indicates $\mathrm{S}=\mathrm{O}$ bands overlapped with broad $\mathrm{Si}-\mathrm{O}-\mathrm{Si}$ in the same area. Even though $\mathrm{S}=\mathrm{O}$ bands overlapped with $\mathrm{Si}-\mathrm{O}-\mathrm{Si}$ vibration, we can assume that the appearance of sharp peaks in the catalysts with more GPTMS-AS content indicates the presence of sulfonic acid groups in the catalysts. $\mathrm{SiO}_{2}-\mathrm{SO}_{3} \mathrm{H}(5)$ shows the sharpest peak in this area, indicating the highest value of sulfonic acid groups.

Hydrolyzed methoxy groups of GPTMS can react with silanol groups of silica while the epoxy ring reacts with organic molecules giving hybrid organic-inorganic networks. The epoxy ring can easily be opened with a nucleophile group such as an amine group at room temperature. The amine group of an organic substance was acidified with formic acid to promote the epoxy ringopening and provide suitable $\mathrm{pH}$ for hydrolysis and

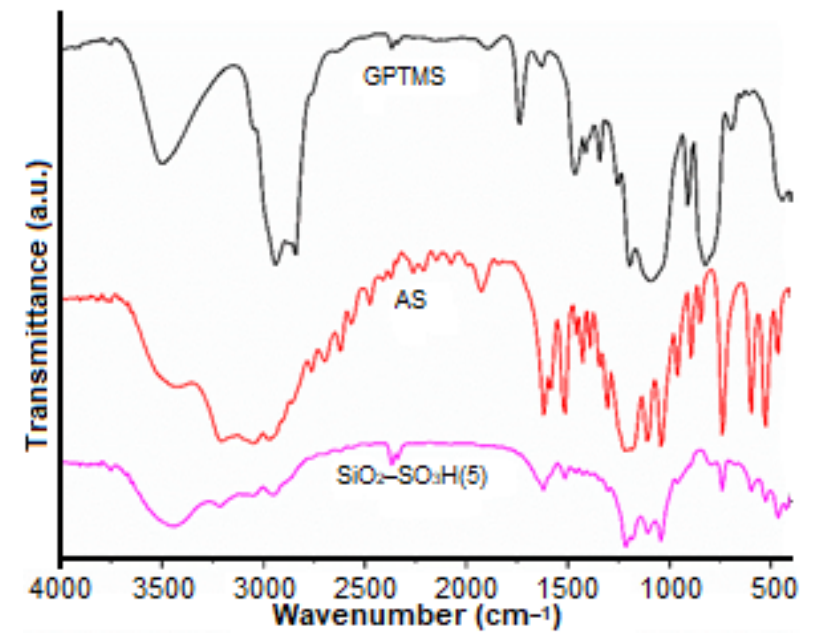

Fig 2. FTIR spectra of GPTMS, AS, and $\mathrm{SiO}_{2}-\mathrm{SO}_{3} \mathrm{H}(5)$

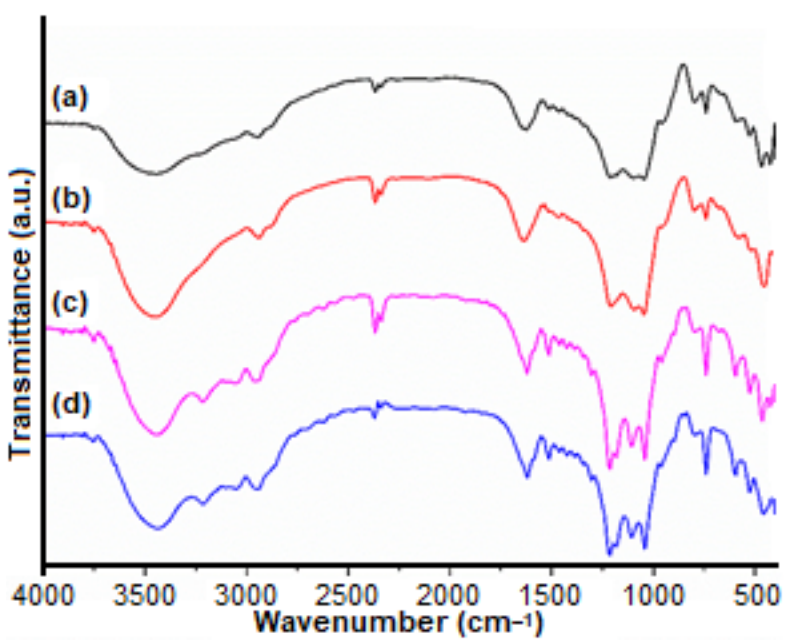

Fig 3. FTIR spectra of (a) $\mathrm{SiO}_{2}-\mathrm{SO}_{3} \mathrm{H}(3)$, (b) $\mathrm{SiO}_{2}-\mathrm{SO}_{3} \mathrm{H}(4)$; (c) $\mathrm{SiO}_{2}-\mathrm{SO}_{3} \mathrm{H}(5)$; and (d) $\mathrm{SiO}_{2}-\mathrm{SO}_{3} \mathrm{H}(6)$

condensation with silicate [14]. The reaction of GPTMS and AS are shown in Fig. 4(a). Hydrolysis of silicate produces silanol groups (Fig. 4(b)) at the same time as hydrolysis of GPTMS-AS (Fig. 4(c)) produced from the previous reaction. Silanols from silicate and GPTMS-AS can undergo condensation to form a silica network (Fig. $4(d))$.

A scanning electron microscope (SEM) was used to characterize the particles' morphology, shape, and size. Fig. 5 and 6 show SEM images and particle size distribution of catalysts. The surface of the particles was not smooth because of the presence of organic moieties. GPTMS-AS addition will loosen the gel network and 


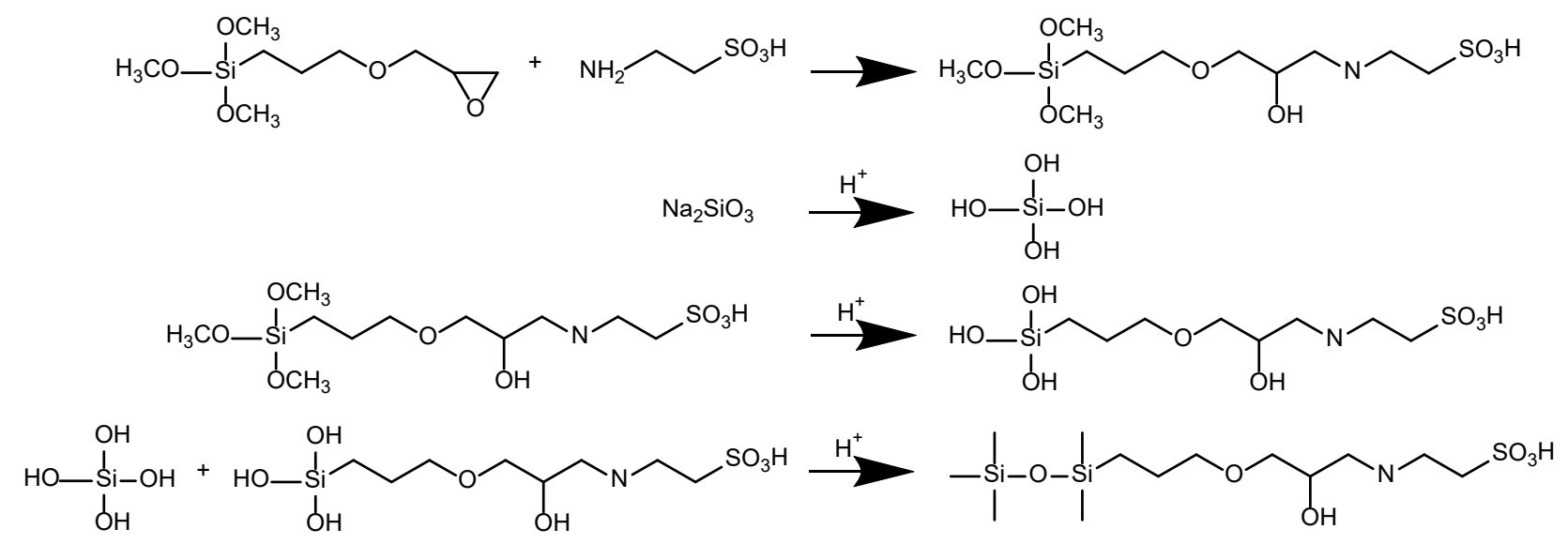

Fig 4. Reaction model of catalyst synthesis

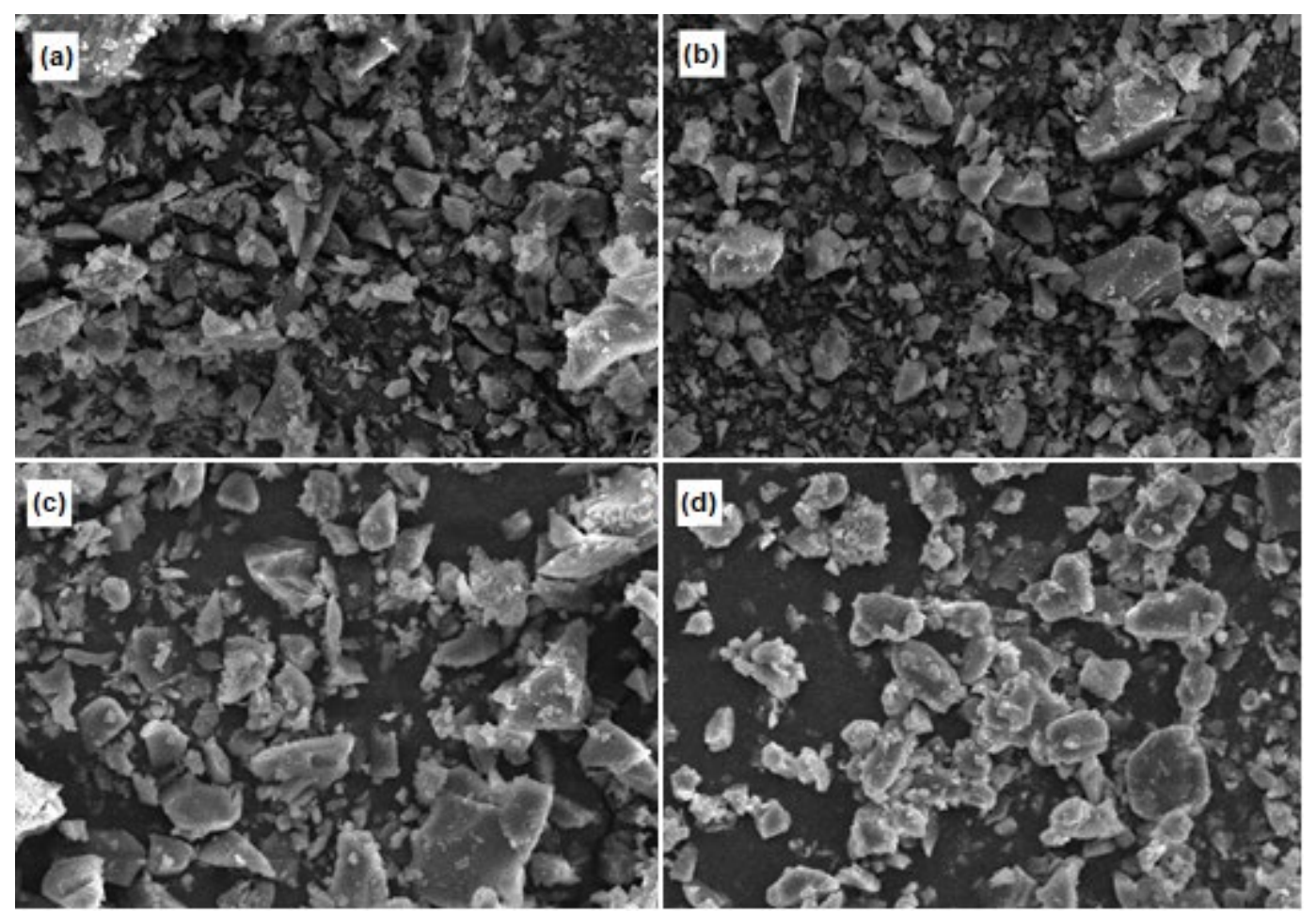

Fig 5. $\mathrm{SEM}$ images of (a) $\mathrm{SiO}_{2}-\mathrm{SO}_{3} \mathrm{H}(3)$, (b) $\mathrm{SiO}_{2}-\mathrm{SO}_{3} \mathrm{H}(4)$; (c) $\mathrm{SiO}_{2}-\mathrm{SO}_{3} \mathrm{H}(5)$; and (d) $\mathrm{SiO}_{2}-\mathrm{SO}_{3} \mathrm{H}(6)$

increase the particle size because of the organic sites in the significant difference between all catalysts. The particles are spheres, and the size distribution with increasing GPTMS-AS is around 3.66, 4.10, 4.36, and $4.40 \mu \mathrm{m}$. Catalyst with more organic content $\left(\mathrm{SiO}_{2}-\mathrm{SO}_{3} \mathrm{H}(6)\right)$ showed a larger particle size than catalysts with less organic content $\left(\mathrm{SiO}_{2}-\mathrm{SO}_{3} \mathrm{H}(3)\right)$.

EDX analysis of catalysts showed the presence of $\mathrm{S}$ and $\mathrm{N}$ elements which is part of AS. The existence of these elements indicates the successful reaction of GPTMS and
AS. $\mathrm{N}$ and $\mathrm{S}$ elements observed from the surface of particles were found around $5-7 \%$ and 5-8\%, respectively. The highest amount of $\mathrm{N}$ and $\mathrm{S}$ elements was found in $\mathrm{SiO}_{2}-\mathrm{SO}_{3} \mathrm{H}(5)$, suggesting high acid sites. From the mapping images of the $\mathrm{SiO}_{2}-\mathrm{SO}_{3} \mathrm{H}(6)$ catalyst in Fig. 7, it can be observed that all compounds were fairly distributed around silica particles. The acid content of catalysts was also determined using the titration method. Excess of $\mathrm{NaOH}$ solution was used to measure the total of acidic groups in catalysts. After equilibrium 

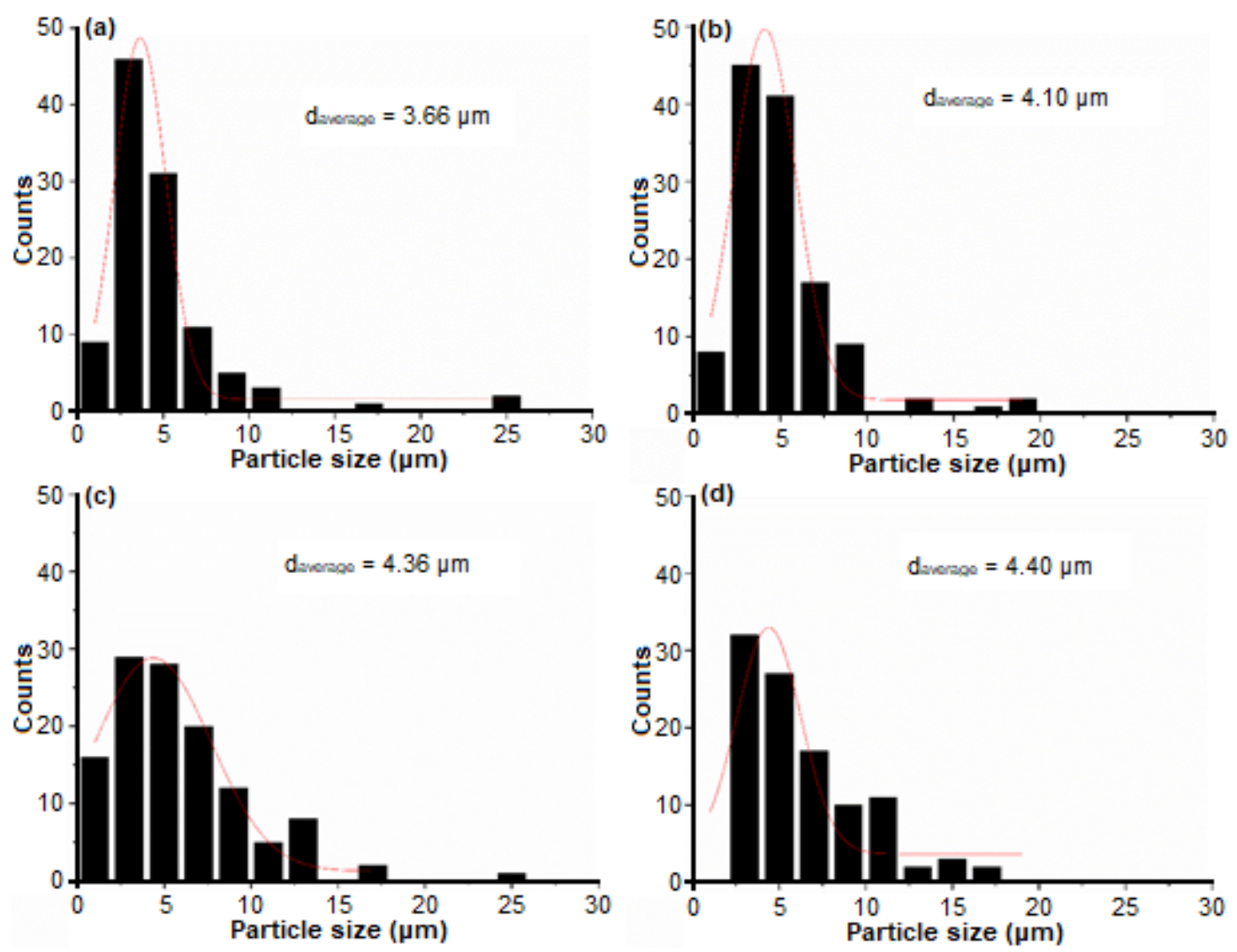

Fig 6. Particle size distribution of (a) $\mathrm{SiO}_{2}-\mathrm{SO}_{3} \mathrm{H}(3)$, (b) $\mathrm{SiO}_{2}-\mathrm{SO}_{3} \mathrm{H}(4)$; (c) $\mathrm{SiO}_{2}-\mathrm{SO}_{3} \mathrm{H}(5)$; and (d) $\mathrm{SiO}_{2}-\mathrm{SO}_{3} \mathrm{H}(6)$
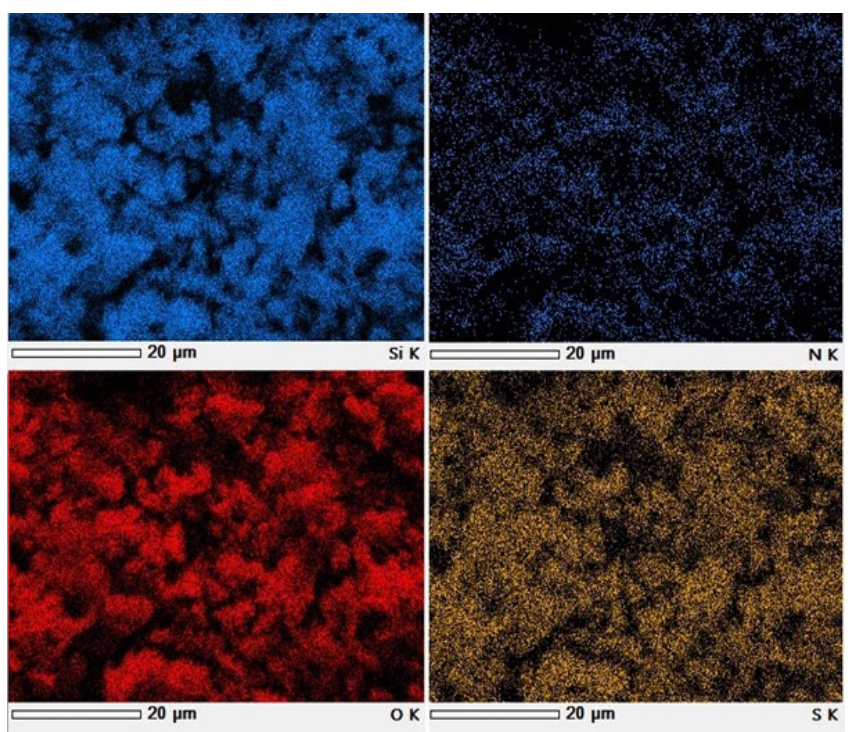

Fig 7. Mapping images of $\mathrm{SiO}_{2}-\mathrm{SO}_{3} \mathrm{H}(6)$

was reached, the solution was back titrated with $\mathrm{HCl}$ solution. Table 2 shows that $\mathrm{SiO}_{2}-\mathrm{SO}_{3} \mathrm{H}(5)$ has the highest acid content $\left(1.02 \mathrm{mmol} \mathrm{g}^{-1}\right)$ even though the GPTMS-AS added was less than on $\mathrm{SiO}_{2}-\mathrm{SO}_{3} \mathrm{H}(6)$. Excessive content of organic network might cause steric hindrance that blocks the accessibility of acid sites to react with incoming molecules. The high content of GPTMS-AS might also cause insufficient polymerization ability of silane sides in GPTMS-AS with silanols of silica precursors. This result agrees with FTIR analysis, showing that $\mathrm{SiO}_{2}-\mathrm{SO}_{3} \mathrm{H}(5)$ has the sharpest peak at 1200 and $1050 \mathrm{~cm}^{-1}$, representing stretching of $\mathrm{S}=\mathrm{O}$ bonds, indicating the highest content of sulfonic acid groups. From EDX results, $\mathrm{SiO}_{2}-\mathrm{SO}_{3} \mathrm{H}(5)$ also has the highest $\mathrm{S}$ element content, further confirming the high amount of sulfonic acid groups as acid sites in catalysts.

The thermogravimetric analysis is provided in Fig. 8. TG analysis was performed to quantify organic moiety to understand the functionalization and analyze catalysts' stability. The total weight loss depended on the amount of organic network. The pattern is similar for all catalysts. The decrease in weight before $100{ }^{\circ} \mathrm{C}$ was caused by removing small organic molecules and adsorbed water from the samples [29]. The weight loss of around $250{ }^{\circ} \mathrm{C}$ was assigned to an organic network 
Table 2. $\mathrm{N}$ and $\mathrm{S}$ elements content by EDX analysis and acid content by titration method

\begin{tabular}{cccc}
\hline \multirow{2}{*}{ Catalyst } & \multicolumn{2}{c}{$\begin{array}{c}\text { Element content }(\%) \\
\text { by EDX analysis }\end{array}$} & \multirow{2}{*}{$\begin{array}{c}\text { Acid content }\left(\mathrm{mmol} \mathrm{g}^{-1}\right) \\
\text { by titration method }\end{array}$} \\
\cline { 2 - 3 } & $\mathrm{N}$ & $\mathrm{S}$ & \\
\hline $\mathrm{SiO}_{2}-\mathrm{SO}_{3} \mathrm{H}(3)$ & 6.42 & 6.66 & 0.56 \\
$\mathrm{SiO}_{2}-\mathrm{SO}_{3} \mathrm{H}(4)$ & 5.16 & 5.27 & 0.86 \\
$\mathrm{SiO}_{2}-\mathrm{SO}_{3} \mathrm{H}(5)$ & 7.18 & 8.15 & 1.02 \\
$\mathrm{SiO}_{2}-\mathrm{SO}_{3} \mathrm{H}(6)$ & 5.79 & 7.75 & 0.66 \\
\hline
\end{tabular}

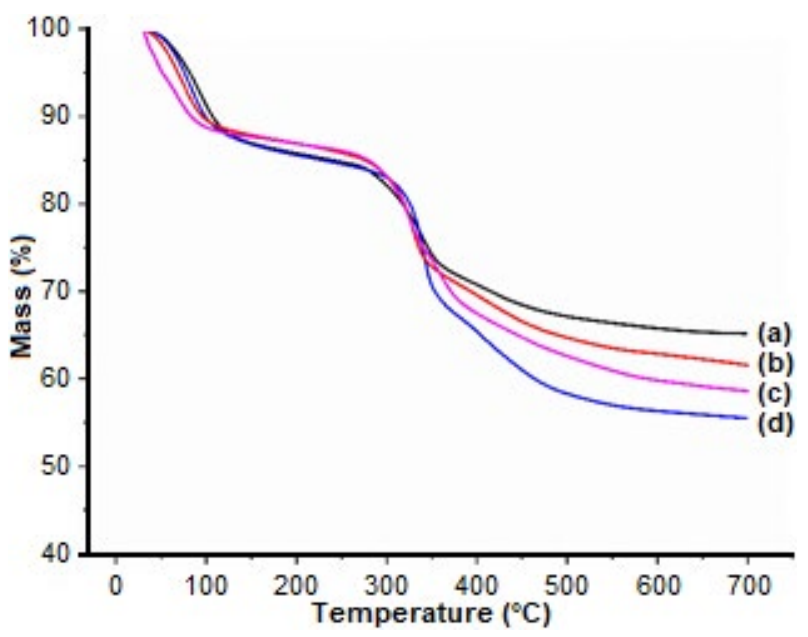

Fig 8. TGA curve of (a) $\mathrm{SiO}_{2}-\mathrm{SO}_{3} \mathrm{H}(3)$, (b) $\mathrm{SiO}_{2}-\mathrm{SO}_{3} \mathrm{H}(4)$; (c) $\mathrm{SiO}_{2}-\mathrm{SO}_{3} \mathrm{H}(5)$; and (d) $\mathrm{SiO}_{2}-\mathrm{SO}_{3} \mathrm{H}(6)$

that undergoes evaporation [30-31]. At those temperatures, organic networks, including acid sites from GPTMS-AS, may be evaporated. The difference in weight loss was due to the amount of GPTMS-AS on the catalyst surface. The weight loss observed for all catalysts from 250-500 ${ }^{\circ} \mathrm{C}$ increased with GPTMS-AS content. $\mathrm{SiO}_{2}-\mathrm{SO}_{3} \mathrm{H}(3)$ showed $16.94 \%$ weight loss at those temperatures, while $\mathrm{SiO}_{2}-\mathrm{SO}_{3} \mathrm{H}(4), \mathrm{SiO}_{2}-\mathrm{SO}_{3} \mathrm{H}(5)$, and $\mathrm{SiO}_{2}-\mathrm{SO}_{3} \mathrm{H}(6)$ showed $20.70,22.75$, and $25.95 \%$ weight loss, respectively. $\mathrm{SiO}_{2}-\mathrm{SO}_{3} \mathrm{H}(6)$ showed the highest weight loss even though the $\mathrm{N}$ and $\mathrm{S}$ content were not the highest. This result may be due to the incomplete reaction of GPTMS and AS, resulting in bond formation between silica and GPTMS, leaving AS out of the framework. Organic decomposition continues slightly till temperature $500 \quad{ }^{\circ} \mathrm{C}$ indicating the complete decomposition of the organic network. There is no weight loss observed above $500{ }^{\circ} \mathrm{C}$ for all materials indicating the presence of stable silica.

\section{Esterification of Levulinic Acid}

Catalytic performance of $\mathrm{SiO}_{2}-\mathrm{SO}_{3} \mathrm{H}$ catalysts was evaluated for esterification of levulinic acid with excess ethanol. The acidity of the catalyst is the main factor determining the catalyst activity for esterification reaction; thus, the catalyst with the highest acid content $\left(\mathrm{SiO}_{2}-\mathrm{SO}_{3} \mathrm{H}(5)\right)$ was first used to determine the optimum conditions. Different reaction parameters such as levulinic acid:ethanol molar ratio and amount of catalyst were examined to optimize the esterification reaction conditions. Fig. 9 shows conversion of levulinic acid esterification with 1:5, 1:10, and 1:15 levulinic acid:ethanol molar ratio, over 5 and $10 \mathrm{wt} \%$ catalysts $\mathrm{SiO}_{2}-\mathrm{SO}_{3} \mathrm{H}(5)$.

As more catalyst was used, the conversion increased progressively, except for the 1:10 molar ratio of levulinic acid to ethanol, where the conversion only slightly increased. Increasing the catalyst amount will supply

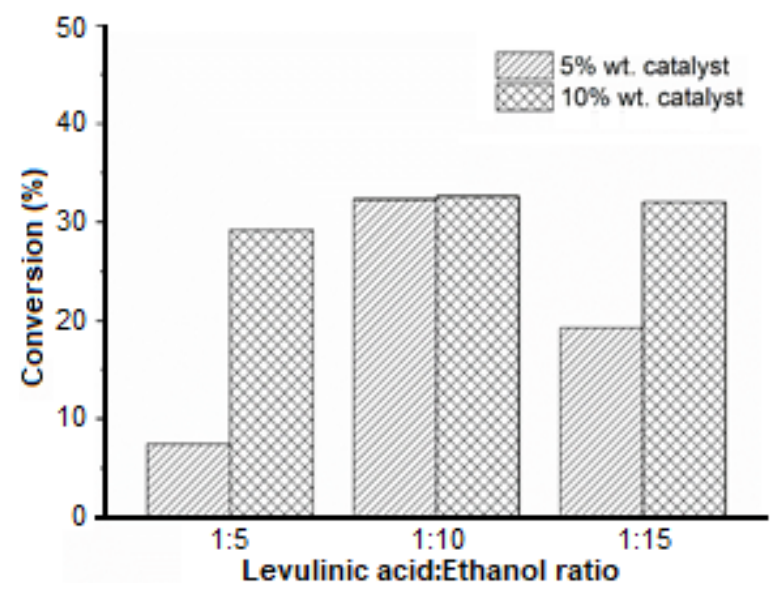

Fig 9. Determination of optimum condition for esterification of levulinic acid using a catalyst with highest acid content $\left(\mathrm{SiO}_{2}-\mathrm{SO}_{3} \mathrm{H}(5)\right)$ 
enough acid sites to improve the esterification of levulinic acid and ethanol. The levulinic acid conversion at varied ethanol amounts increased at 1:10 and decreased at 1:15 molar ratios. As esterification is a reversible reaction, excess alcohol needs to be added to drive the forward reaction. However, too many alcohol supplies could reduce the conversion. Alcohol exists as a reactant and cosolvent to dilute levulinic acid. The redundant alcohol content can shield levulinic acid molecules from reacting with acid sites of catalysts [32]. As a result, a suitable condition is needed to keep the esterification going and optimize the blending condition to minimize the viscosity and limitation of mass transfer in the reaction system [33]. The molar ratio of 1:10 might be the optimum condition for esterification of levulinic acid because it produces the highest conversion for both amounts of catalysts (5 and 10 wt.\%). As the conversion in 5 and $10 \mathrm{wt} . \%$ was only slightly different, $5 \mathrm{wt} . \%$ catalysts were chosen as the optimum catalyst amount.

The total conversion of levulinic acid over time is shown in Fig. 10. All catalysts have the same pattern for conversion at different times of reaction. The highest conversions are reached only after $5 \mathrm{~h}$. The use of catalysts with the highest acid content can accelerate product formation. The $\mathrm{SiO}_{2}-\mathrm{SO}_{3} \mathrm{H}(5)$ catalyst gives the highest conversion (70\%), while $\mathrm{SiO}_{2}-\mathrm{SO}_{3} \mathrm{H}(3)$ and $\mathrm{SiO}_{2}-\mathrm{SO}_{3} \mathrm{H}(4)$ only give $46 \%$ and $65 \%$ conversion. A decrease in conversion (59\%) can be observed in $\mathrm{SiO}_{2}-\mathrm{SO}_{3} \mathrm{H}(6)$ catalyst. This result followed the amount of acid sites, where the highest conversion was achieved from catalyst with highest acid sites. More acid sites give more available sites for levulinic acid and ethanol to interact. Hence, there are more molecules reacted to form ethyl levulinate products. According to the previous report [34], the production of esters is limited by the reversibility and water by-product formation. After some time of reactions, water by-product is accumulated, encouraging the back reaction of esterification, and at $5 \mathrm{~h}$ of reaction, all catalysts exhibit the highest conversion. However, at $6 \mathrm{~h}$ of reaction, the conversion of levulinic acid decreased. This phenomenon might happen because of the occurrence of back-reaction and also the blocking of acid sites by water by-products. The accumulation of levulinic acid and its intermediate on acid sites and the entanglement of organic chains can also cause the decrease of conversion at $6 \mathrm{~h}$ [35].

Compared to previous literature presented in Table 3 , this result was higher than the commercial catalyst reported by Fernandes et al. [21]. For the same reaction

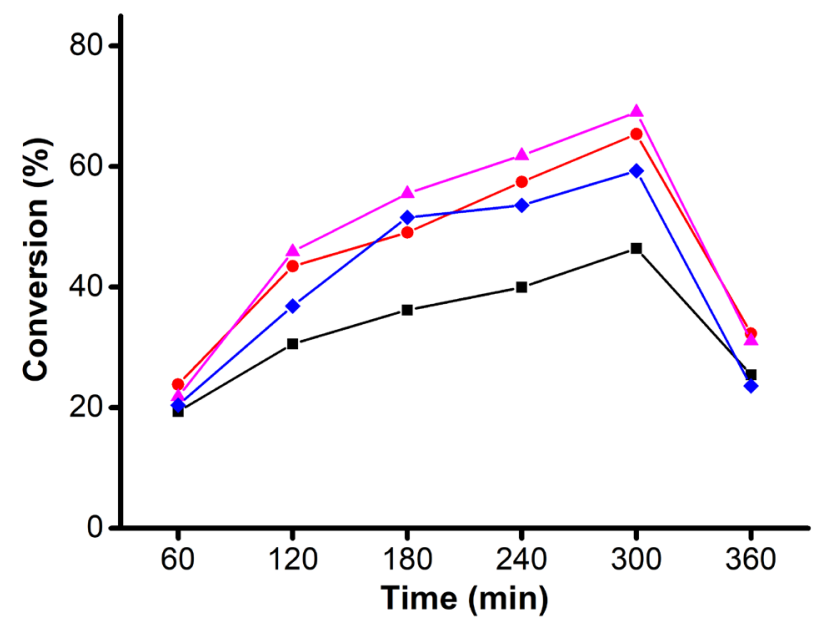

Fig 10. Conversion of levulinic acid over ( $\square$ ) $\mathrm{SiO}_{2}-\mathrm{SO}_{3} \mathrm{H}(3)$, (०) $\mathrm{SiO}_{2}-\mathrm{SO}_{3} \mathrm{H}(4),(\triangle) \mathrm{SiO}_{2}-\mathrm{SO}_{3} \mathrm{H}(5)$, and $(\diamond) \mathrm{SiO}_{2}-\mathrm{SO}_{3} \mathrm{H}(6)$

Table 3. Conversion of levulinic acid esterification over various catalysts from previous reports

\begin{tabular}{lcccccc}
\hline Catalyst & $\begin{array}{c}\text { Levulinic } \\
\text { acid:Ethanol }\end{array}$ & $\begin{array}{c}\text { Catalyst amount } \\
(\%)\end{array}$ & $\begin{array}{c}\text { Temp } \\
\left({ }^{\circ} \mathrm{C}\right)\end{array}$ & $\begin{array}{c}\text { Time } \\
(\mathrm{h})\end{array}$ & $\begin{array}{c}\text { Conversion } \\
(\%)\end{array}$ & Ref. \\
\hline Amberlyst-15 & $1: 5$ & 2.5 & 70 & 5 & 54 & {$[21]$} \\
Sulfonated CNT & $1: 5$ & 2.5 & 70 & 5 & $20-55$ & {$[40]$} \\
Sulfonated carbon & $1: 5$ & 5.0 & 80 & 9 & 58 & {$[37]$} \\
Sulfated $\mathrm{SnO}_{2}$ & $1: 5$ & 2.5 & 70 & 7 & 75 & {$[36]$} \\
Carbon cryogel & $1: 20$ & 5.0 & 78 & 6 & 52 & {$[39]$} \\
$\mathrm{ZSM}_{-12}$ & $1: 1$ & 13.1 & 100 & 24 & 56 & {$[41]$} \\
$\mathrm{SiO}_{2}-\mathrm{SO}_{3} \mathrm{H}(5)$ & $1: 10$ & 5.0 & 70 & 5 & 70 & this work \\
\hline
\end{tabular}


time, Amberlyst-15 generates 54\% conversion. On the other hand, sulfated $\mathrm{SnO}_{2}$ showed higher conversion (75\%) in $7 \mathrm{~h}$, mainly due to a higher acid site [36]. Moreover, the synthesis of the catalyst requires a toxic $\mathrm{H}_{2} \mathrm{SO}_{4}$ solution and a longer esterification reaction time. With the same amount of catalyst, sulfonated carbon gives $58 \%$ conversion only after $9 \mathrm{~h}$ of reaction at $80^{\circ} \mathrm{C}$ [37].

The used catalyst was washed with alcohol and water to remove adsorbed organic species to examine the reusability of the catalysts. Under the optimum condition, three cycles of esterification were conducted. As shown in Fig. 11, all catalysts showed a decrease in conversion after the third circle. Conversion of $\mathrm{SiO}_{2}-\mathrm{SO}_{3} \mathrm{H}(4)$ decreases from 65 to $51 \%$ after the third cycle, while $\mathrm{SiO}_{2}-\mathrm{SO}_{3} \mathrm{H}(5)$ and $\mathrm{SiO}_{2}-\mathrm{SO}_{3} \mathrm{H}(6)$ decrease from 70 to $50 \%$ and 59 to $50 \%$, respectively. In addition, $\mathrm{SiO}_{2}-\mathrm{SO}_{3} \mathrm{H}(3)$ shows a recognizable reduction in conversion after the third cycle (from 46 to 13\%). These decreases in conversions are attributed to the loss of acid sites into the alcohol media during repeated use, as previously reported by Kuwahara et al. [38].

\section{Kinetic Study}

The reaction order and rate constants were determined by integration of Eq. (6) for pseudo-zeroth order $(\alpha=0)$, pseudo-first-order $(\alpha=1)$, and pseudosecond-order $(\alpha=2)$. The equations are shown in Eq. (7), (8), and (9), respectively.

$$
\begin{aligned}
& \mathrm{xC}_{\mathrm{A}_{0}}=\mathrm{kt} \\
& -\ln (1-\mathrm{x})=\mathrm{kt} \\
& \frac{1}{(1-\mathrm{x})}=\mathrm{C}_{\mathrm{A}_{0}} \mathrm{kt}
\end{aligned}
$$

The rate constant $(\mathrm{k})$ for the pseudo-zeroth-order reaction was determined as the slope in the plot of $x$ vs. $t$, and the rate constant $(\mathrm{k})$ for the pseudo-first-order reaction was determined as the slope of the $-\ln (1-x)$ vs. $t$ plot. For pseudo-second-order reaction, the rate constant (k) was calculated from the slope of $1 /(1-x)$ vs. $t$.

Experimental data was used to calculate the rate constant and determine the reaction order by linear fitting. Zainol et al. [39] determined the kinetic model of levulinic acid using a carbon catalyst. The observed data were directly fitted with a pseudo-first-order kinetic model. For better determination, other kinetic models were also fitted. The kinetic model could be determined by comparing observed and predicted data accuracy for three kinetic models. Fig. 12 shows the kinetic plots obtained from levulinic acid esterification using $\mathrm{SiO}_{2}-\mathrm{SO}_{3} \mathrm{H}$ catalysts. Based on the data shown in Table 4 , all catalysts fitted the best with a pseudo-first-order kinetic plot with the highest $\mathrm{R}^{2}$ value compared to other kinetic plots. The predicted and observed data showed a small deviation in pseudo-first-order than pseudozeroth and pseudo-second-order. Therefore, the kinetic models of levulinic acid esterification with $\mathrm{SiO}_{2}-\mathrm{SO}_{3} \mathrm{H}$ catalyst could be classified as pseudo-first-order reactions.

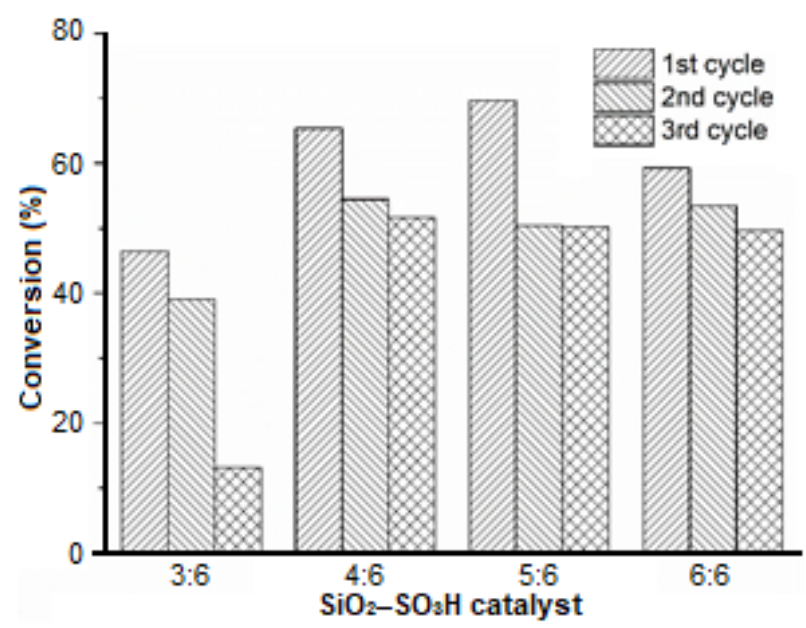

Fig 11. Reusability of $\mathrm{SiO}_{2}-\mathrm{SO}_{3} \mathrm{H}$ catalysts

Table 4. Kinetic parameters of levulinic acid esterification over $\mathrm{SiO}_{2}-\mathrm{SO}_{3} \mathrm{H}$ catalysts

\begin{tabular}{lcccc}
\hline \multirow{2}{*}{ Catalysts } & $\begin{array}{c}\text { Pseudo-Zeroth- } \\
\text { Order }\end{array}$ & $\begin{array}{c}\text { Pseudo-First- } \\
\text { Order }\end{array}$ & $\begin{array}{c}\text { Pseudo-Second- } \\
\text { Order }\end{array}$ & $\begin{array}{c}\text { Pseudo-First- } \\
\text { Order }\end{array}$ \\
\cline { 2 - 5 } & $\mathrm{R}^{2}$ & $\mathrm{R}^{2}$ & $\mathrm{R}^{2}$ & $\mathrm{k}\left(10^{-3} \mathrm{~min}^{-1}\right)$ \\
\hline $\mathrm{SiO}_{2}-\mathrm{SO}_{3} \mathrm{H}(3)$ & 0.83 & 0.92 & 0.50 & 2.36 \\
$\mathrm{SiO}_{2}-\mathrm{SO}_{3} \mathrm{H}(4)$ & 0.88 & 0.97 & 0.83 & 3.78 \\
$\mathrm{SiO}_{2}-\mathrm{SO}_{3} \mathrm{H}(5)$ & 0.88 & 0.98 & 0.90 & 4.14 \\
$\mathrm{SiO}_{2}-\mathrm{SO}_{3} \mathrm{H}(6)$ & 0.87 & 0.95 & 0.75 & 3.36 \\
\hline
\end{tabular}



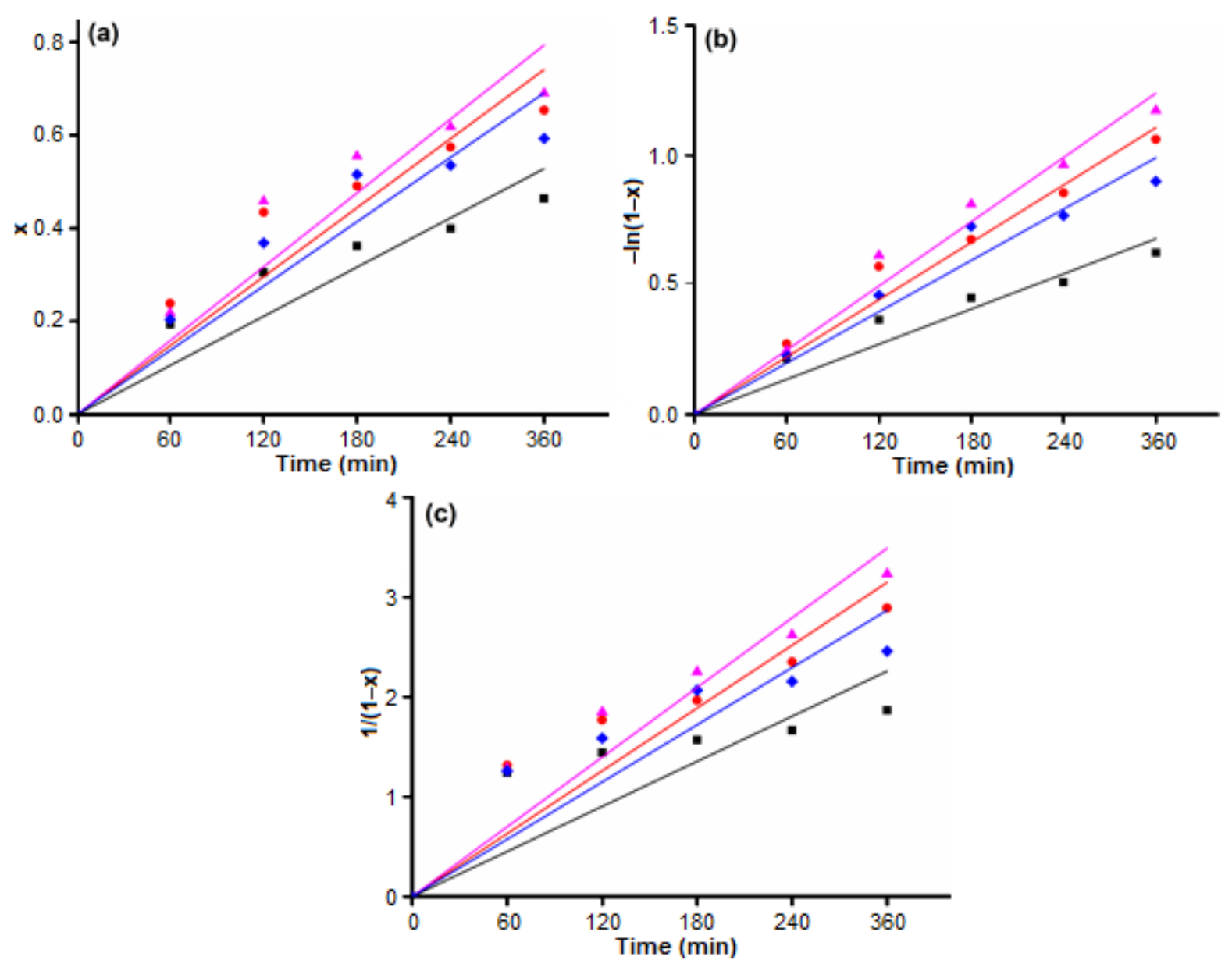

Fig 12. Kinetic plots for (a) pseudo-zeroth-order, (b) pseudo-first-order, and (c) and pseudo-second-order of ( $\square$ ) $\mathrm{SiO}_{2}-\mathrm{SO}_{3} \mathrm{H}(3),(\circ) \mathrm{SiO}_{2}-\mathrm{SO}_{3} \mathrm{H}(4),(\triangle) \mathrm{SiO}_{2}-\mathrm{SO}_{3} \mathrm{H}(5)$, and $(\diamond) \mathrm{SiO}_{2}-\mathrm{SO}_{3} \mathrm{H}(6)$

The slope acquired from the pseudo-first-order linear equation determined the rate constant $(\mathrm{k})$ for each catalyst. As expected, the catalyst with the highest acidity has a higher rate constant.

\section{- CONCLUSION}

In summary, we have shown that sulfonate functionalized silicas $\left(\mathrm{SiO}_{2}-\mathrm{SO}_{3} \mathrm{H}\right)$ have been successfully synthesized with a simple one-pot and green process using the solution of $\mathrm{Na}_{2} \mathrm{SiO}_{3}$, 3-glycidoxypropyltrimethoxysilane (GPTMS), and 2-aminoethanesulfonic acid (AS) as the silica source, the coupling agent, and sulfonic acid group source, respectively. The epoxide groups of GPTMS react with amine groups from AS by a ring-opening reaction. The $\mathrm{SiO}_{2}-\mathrm{SiO}_{3} \mathrm{H}$ produced is a prospective solid acid catalyst to any reaction for producing renewable fuels. $\mathrm{SiO}_{2}-\mathrm{SO}_{3} \mathrm{H}(5)$ is the most effective catalyst for esterification of levulinic acid with 70\% conversion and high reusability; three cycles of reuse did not give a significant conversion decrease.

\section{- ACKNOWLEDGMENTS}

We acknowledge the Universitas Gadjah Mada and PMDSU scholarship by the Ministry of the Higher Education Republic of Indonesia under grant No. 6314/UN1/DITLIT/DIT-LIT/LT/2019.

\section{- REFERENCES}

[1] Malins, K., Kampars, V., Kampare, R., Prilucka, J., Brinks, J., Murnieks, R., and Apseniece, L., 2014, Properties of rapeseed oil fatty acid alkyl esters derived from different alcohols, Fuel, 137, 28-35.

[2] Liu, Y., Huo, P., Ren, J., and Wang, G., 2017, Organic-inorganic hybrid proton-conducting 
electrolyte membranes based on sulfonated poly(arylene ether sulfone) and $\mathrm{SiO}_{2}-\mathrm{SO}_{3} \mathrm{H}$ network for fuel cells, High Perform. Polym., 29 (9), 10371048.

[3] Diagboya, P.N.E., and Dikio, E.D., 2018, Silica-based mesoporous materials; emerging designer adsorbents for aqueous pollutants removal and water treatment, Microporous Mesoporous Mater., 266, 252-267.

[4] Berbar, Y., Hammache, Z.E., Bensaadi, S., Soukeur, R., Amara, M., and Van der Bruggen, B., 2019, Effect of functionalized silica nanoparticles on sulfonated polyethersulfone ion exchange membrane for removal of lead and cadmium ions from aqueous solutions, J. Water Process Eng., 32, 100953.

[5] Ziarani, G.M., Badiei, A., Hassanzadeh, M., and Mousavi, S., 2014, Synthesis of 1,8-dioxodecahydroacridine derivatives using sulfonic acid functionalized silica $\left(\mathrm{SiO}_{2}-\mathrm{Pr}-\mathrm{SO}_{3} \mathrm{H}\right)$ under solvent free conditions, Arabian J. Chem., 7 (3), 335-339.

[6] Xiong, Y., Zhang, Z., Wang, X., Liu, B., and Lin, J., 2014, Hydrolysis of cellulose in ionic liquids catalyzed by a magnetically-recoverable solid acid catalyst, Chem. Eng. J., 235, 349-355.

[7] Palla-Rubio, B., Araújo-Gomes, N., FernándezGutiérrez, M., Rojo, L., Suay, J., Gurruchaga, M., and Goñi, I., 2019, Synthesis and characterization of silica-chitosan hybrid materials as antibacterial coatings for titanium implants, Carbohydr. Polym., 203, 331-341.

[8] Rahman, I.A., and Padavettan, V., 2012, Synthesis of silica nanoparticles by sol-gel: Size-dependent properties, surface modification, and applications in silica-polymer nanocomposites-A review, $J$. Nanomater., 2012, 132424.

[9] Nhavene, E.P.F., da Silva, W.M., Trivelato Junior, R.R., Gastelois, P.L., Venâncio, T., Nascimento, R., Batista, R.J.C., Machado, C.R., Macedo, W.A.A., and de Sousa, E.M.B., 2018, Chitosan grafted into mesoporous silica nanoparticles as benznidazol carrier for Chagas diseases treatment, Microporous Mesoporous Mater., 272, 265-275.

[10] Parale, V.G., Kim, T., Lee, K.Y., Phadtare, V.D., Dhavale, R.P., Jung, H.N.R., and Park, H.H., 2019,
Hydrophobic $\mathrm{TiO}_{2}-\mathrm{SiO}_{2}$ composite aerogels synthesized via in situ epoxy-ring opening polymerization and sol-gel process for enhanced degradation activity, Ceram. Int., 46 (4), 49394946.

[11] Vueva, Y., Connell, L.S., Chayanun, S., Wang, D., McPhail, D.S., Romer, F., Hanna, J.V., and Jones, J.R., 2018, Silica/alginate hybrid biomaterials and assessment of their covalent coupling, Appl. Mater. Today, 11, 1-12.

[12] Shao, Z., Wu, G., Cheng, X., and Zhang, Y., 2012, Rapid synthesis of amine cross-linked epoxy and methyl co-modified silica aerogels by ambient pressure drying, J. Non-Cryst. Solids, 358 (18-19), 2612-2615.

[13] Vreugdenhil, A.J., Gelling, V.J., Woods, M.E., Schmelz, J.R., and Enderson, B.P., 2008, The role of crosslinkers in epoxy-amine crosslinked silicon solgel barrier protection coatings, Thin Solid Films, 517 (2), 538-543.

[14] de Luca, M.A., Martinelli, M., and Barbieri, C.C.T., 2009, Hybrid films synthesised from epoxidised castor oil, $\gamma$-glycidoxypropyltrimethoxysilane and tetraethoxysilane, Prog. Org. Coat., 65 (3), 375-380.

[15] Gabrielli, L., Russo, L., Poveda, A., Jones, J.R., Nicotra, F., Jiménez-Barbero, J., and Cipolla, L., 2013, Epoxide opening versus silica condensation during sol-gel hybrid biomaterial synthesis, Chem. Eur. J., 19 (24), 7856-7864.

[16] An, S., Sun, Y., Song, D., Zhang, Q., Guo, Y., and Shang, Q., 2016, Arenesulfonic acid-functionalized alkyl-bridged organosilica hollow nanospheres for selective esterification of glycerol with lauric acid to glycerol mono- and dilaurate, J. Catal., 342, 40-54.

[17] Sierra, I., and Pérez-Quintanilla, D., 2013, Heavy metal complexation on hybrid mesoporous silicas: An approach to analytical applications, Chem. Soc. Rev., 42 (9), 3792-3807.

[18] Da'na, E., 2017, Adsorption of heavy metals on functionalized-mesoporous silica: A review, Microporous Mesoporous Mater., 247, 145-157.

[19] Chen, J., Chen, J., Zhang, X., Gao, J., and Yang, Q., 2016, Efficient and stable $\mathrm{PS}_{-} \mathrm{SO}_{3} \mathrm{H} / \mathrm{SiO}_{2}$ hollow 
nanospheres with tunable surface properties for acid catalyzed reactions, Appl. Catal., A, 516, 1-8.

[20] Hayes, D.J., Ross, J., Hayes, H.B., and Fitzpatrick, S., 2005, "The Biofine Process - Production of Levulinic Acid, Furfural, and Formic Acid from Lignocellulosic Feedstocks" in Biorefineries-Industrial Processes and Products: Status Quo and Future Directions, Eds. Kamm, B., Gruber, P.R., and Kamm, M., Wiley-VCH Verlag GmbH \& Co. KGaA, Weinheim, 139-164.

[21] Fernandes, D.R., Rocha, A.S., Mai, E.F., Mota, C.J.A., and da Silva, V.T., 2012, Levulinic acid esterification with ethanol to ethyl levulinate production over solid acid catalysts, Appl. Catal., A, 425-426, 199-204.

[22] Benak, K.R., Dominguez, L., Economy, J., and Mangun, C.L., 2002, Sulfonation of pyropolymeric fibers derived from phenol-formaldehyde resins, Carbon, 40 (13), 2323-2332.

[23] Trinh, B.M., and Mekonnen, T., 2018, Hydrophobic esterification of cellulose nanocrystals for epoxy reinforcement, Polymer, 155, 64-74.

[24] Gupta, G., Pathak, S.S., and Khanna, A.S., 2012, Anticorrosion performance of eco-friendly silane primer for coil coating applications, Prog. Org. Coat., 74 (1), 106-114.

[25] Shajesh, P., Smitha, S., Aravind, P.R., and Warrier, K.G.K., 2009, Synthesis, structure and properties of cross-linked $\mathrm{R}\left(\mathrm{SiO}_{1.5}\right) / \mathrm{SiO}_{2}(\mathrm{R}=3$-glycidoxypropyl) porous organic inorganic hybrid networks dried at ambient pressure, J. Colloid Interface Sci., 336 (2), 691-697.

[26] Heo, J.H., Lee, J.W., Lee, B., Cho, H.H., Lim, B., and Lee, J.H., 2017, Chemical effects of organo-silanized $\mathrm{SiO}_{2}$ nanofillers on epoxy adhesives, J. Ind. Eng. Chem., 54, 184-189.

[27] Elsayed, I., Mashaly, M., Eltaweel, F., Jackson, M.A., and Hassan, E.B., 2018, Dehydration of glucose to 5hydroxymethylfurfural by a core-shell $\mathrm{Fe}_{3} \mathrm{O}_{4} @ \mathrm{SiO}_{2^{-}}$ $\mathrm{SO}_{3} \mathrm{H}$ magnetic nanoparticle catalyst, Fuel, 221, 407416.

[28] Ambrożewicz, D., Ciesielczyk, F., Nowacka, M., Karasiewicz, J., Piasecki, A., MacIejewski, H., and Jesionowski, T., 2013, Fluoroalkylsilane versus alkylsilane as hydrophobic agents for silica and silicates, J. Nanomater., 2013, 631938.

[29] Han, X., Zhu, G., Ding, Y., Miao, Y., Wang, K., Zhang, H., Wang, Y., and Liu, S.B., 2019, Selective catalytic synthesis of glycerol monolaurate over silica gel-based sulfonic acid functionalized ionic liquid catalysts, Chem. Eng. J., 359, 733-745.

[30] González, M.D., Salagre, P., Taboada, E., Llorca, J., Molins, E., and Cesteros, Y., 2013, Sulfonic acidfunctionalized aerogels as high resistant to deactivation catalysts for the etherification of glycerol with isobutene, Appl. Catal., B, 136-137, 287-293.

[31] de Oliveira, F.M., Segatelli, M.G., and Tarley, C.R.T., 2016, Hybrid molecularly imprinted poly(methacrylic acid-TRIM)-silica chemically modified with (3glycidyloxypropyl)trimethoxysilane for the extraction of folic acid in aqueous medium, Mater. Sci. Eng., C, 59, 643-651.

[32] Niu, S., Ning, Y., Lu, C., Han, K., Yu, H., and Zhou, Y., 2018, Esterification of oleic acid to produce biodiesel catalyzed by sulfonated activated carbon from bamboo, Energy Convers. Manage., 163, 59-65.

[33] Mahmoud, H.R., 2019, Bismuth silicate $\left(\mathrm{Bi}_{4} \mathrm{Si}_{3} \mathrm{O}_{12}\right.$ and $\mathrm{Bi}_{2} \mathrm{SiO}_{5}$ ) prepared by ultrasonic-assisted hydrothermal method as novel catalysts for biodiesel production via oleic acid esterification with methanol, Fuel, 256, 115979.

[34] Cannilla, C., Bonura, G., Costa, F., and Frusteri, F., 2018, Biofuels production by esterification of oleic acid with ethanol using a membrane assisted reactor in vapour permeation configuration, Appl. Catal., A, 566, 121-129.

[35] Liu, Y., Lotero, E., and Goodwin, J.G., 2006, Effect of carbon chain length on esterification of carboxylic acids with methanol using acid catalysis, J. Catal., 243 (2), 221-228.

[36] Popova, M., Shestakova, P., Lazarova, H., Dimitrov, M., Kovacheva, D., Szegedi, A., Mali, G., Dasireddy, V., Likozar, B., Wilde, N., and Gläser, R., 2018, Efficient solid acid catalysts based on sulfated tin oxides for liquid phase esterification of levulinic 
acid with ethanol, Appl. Catal., A, 560, 119-131.

[37] Li, N., Wang, Q., Ullah, S., Zheng, X.C., Peng, Z.K., and Zheng, G.P., 2019, Esterification of levulinic acid in the production of fuel additives catalyzed by porous sulfonated carbon derived from pine needle, Catal. Commun., 129, 105755.

[38] Kuwahara, Y., Kaburagi, W., Nemoto, K., and Fujitani, T., 2014, Esterification of levulinic acid with ethanol over sulfated Si-doped $\mathrm{ZrO}_{2}$ solid acid catalyst: Study of the structure-activity relationships, Appl. Catal., A, 476, 186-196.

[39] Zainol, M.M., Amin, N.A.S., and Asmadi, M., 2019, Kinetics and thermodynamic analysis of levulinic acid esterification using lignin-furfural carbon cryogel catalyst, Renewable Energy, 130, 547-557.

[40] Oliveira, B.L., and da Silva, V.T., 2014, Sulfonated carbon nanotubes as catalysts for the conversion of levulinic acid into ethyl levulinate, Catal. Today, 234, 257-263.

[41] Imyen, T., Saenluang, K., Dugkhuntod, P., and Wattanakit, C., 2021, Investigation of ZSM-12 nanocrystals evolution derived from aluminosilicate nanobeads for sustainable production of ethyl levulinate from levulinic acid esterification with ethanol, Microporous Mesoporous Mater., 312, 110768. 